\title{
Correction to: Iron chelation may harm patients with COVID-19
}

\author{
Michael D. Garrick ${ }^{1,2}$ (D) Andrew J. Ghio ${ }^{3}$
}

Published online: 17 March 2021

(C) Springer-Verlag GmbH Germany, part of Springer Nature 2021

\section{Correction to: European Journal of Clinical Pharmacology} (2021) 77:265-266 https://doi.org/10.1007/s00228-020-02987-w

Funding MDG's research is supported by grant R01 DK109717 from the National Institute of Diabetes and Digestive and Kidney Diseases and the Office of Dietary Supplements.

Publisher's note Springer Nature remains neutral with regard to jurisdictional claims in published maps and institutional affiliations.

The online version of the original article can be found at https://doi.org/ 10.1007/s00228-020-02987-w

Michael D. Garrick mgarrick@buffalo.edu

1 Department of Biochemistry, Jacobs School of Medicine and Biomedical Sciences, University at Buffalo, Buffalo, NY, USA

2 Department of Pediatrics, Jacobs School of Medicine and Biomedical Sciences, University at Buffalo, Buffalo, NY, USA

3 US Environmental Protection Agency, Chapel Hill, NC, USA 